\title{
Task-specific bench model training versus basic laparoscopic skills training for laparoscopic radical prostatectomy: a randomized controlled study
}

\author{
Robert Sabbagh, BPharm, MSc, MD; ${ }^{*}$ Suman Chatterjee, MD; ${ }^{\dagger}$ Arun Chawla, MD; ${ }^{\dagger}$ Anil Kapoor, MD; ${ }^{+}$ \\ Edward D. Matsumoto, MD, M.Ed ${ }^{\dagger}$
}

See related article on page 31

\begin{abstract}
Background: Performing a laparoscopic urethrovesical anastomosis (LUA) after a radical prostatectomy is technically challenging for the novice laparoscopic surgeon. We developed a low-fidelity urethrovesical model (UVM) to allow a urologist to practise this critical step. The aim of our study was to compare the effect of task-specific bench model training (anastomotic suturing on the UVM) with that of basic laparoscopic suturing on intracorporeal urethrovesical anastomosis performance.

Methods: We recruited 28 senior surgical residents, fellows or staff surgeons for this prospective, single-blinded, randomized controlled study. We randomly assigned participants to an intervention group practising LUA on the UVM or to a control group practising basic laparoscopic suturing and knot-tying on a foam pad. After practising, we videotaped participants performing 5 intracorporeal interrupted sutures on a foam pad and a LUA on the UVM. A blinded expert scored the videotaped performance using a laparoscopic suturing checklist $(\mathrm{CL})$ and a global rating scale (GRS), and timed the performance.

Results: On the foam pad suturing task, the group that trained on the UVM had significantly higher CL scores (10.9 v. 8.1, $p=0.017)$. On the LUA task, the group that trained on the UVM had significantly higher $\mathrm{CL}$ scores (10.9 v. 8.1, $p=0.017$ ), GRS (29.6 v. 22.8, $p=0.005$ ) and shorter times (27.6 v. $38.3 \mathrm{~min}$, $p=0.004)$ than the control group.

Conclusion: Our task-specific bench model was shown to be superior to basic laparoscopic suturing drills on a foam pad.
\end{abstract}

Can Urol Assoc J 2009;3(1):22-30

\section{Résumé}

Généralités : L'anastomose urétrovésicale par voie laparoscopique (AUL) suivant une prostatectomie radicale pose certaines difficultés techniques au chirurgien peu expérimenté avec la laparoscopie. Nous avons créé un modèle urétrovésical basse-fidélité (MUB) permettant aux urologues de pratiquer cette étape cruciale de l'intervention. Le but de l'étude était de comparer l'impact d'exercices avec un modèle spécifique à la tâche (sutures anasto- motiques sur le modèle urétrovésical) et d'exercices de sutures laparoscopiques sur l'aptitude à effectuer des anastomoses urétrovésicales intracorporelles.

Méthodologie : Vingt-huit résidents séniors en chirurgie, chercheursboursiers et chirurgiens ont été recrutés pour cette étude prospective et contrôlée, menée à simple insu avec répartition aléatoire. Les participants ont été répartis au hasard en 2 groupes, soit un groupe qui a pratiqué l'anastomose urétrovésicale sur le MUB et un groupe témoin qui a pratiqué les sutures laparoscopiques et la formation de nœuds sur un coussinet de mousse. Après la pratique, les participants ont été filmés pendant qu'ils effectuaient 5 suturations intracorporelles interrompues sur un coussinet de mousse et une anastomose urétrovésicale par laparoscopie à l'aide du modèle urétrovésical. Un expert ne connaissant pas le type d'exercices utilisé a ensuite évalué les chirurgiens à l'aide d'une liste de vérification des éléments clés d'une suturation laparoscopique (LV), d'un score global et du temps requis pour les suturations.

Résultats : Lors de la tâche de suturation avec coussinet de mousse, le groupe qui avait pratiqué à l'aide du modèle urétrovésical a obtenu des scores LV significativement plus élevés (10,9 contre $8,1 ; p=0,017)$. Quant à la tâche d'anastomose urétrovésicale par laparoscopie, le groupe qui avait pratiqué sur le modèle urétrovésical a également obtenu des scores LV significativement plus élevés $(10,9$ contre 8,$1 ; p=0.017)$, mais aussi un score global plus élevé (29,6 contre 22,8, $p=0,005)$, et il a effectué la tâche en moins de temps $(27,6$ minutes contre 38,3 minutes, $p=0,004)$ par rapport au groupe témoin.

Conclusion : Nous avons élaboré un modèle spécifique à la tâche qui s'est révélé supérieur aux exercices de suturation laparoscopique sur coussinet de mousse.

\section{Introduction}

Laparoscopic radical prostatectomy (LRP) has been introduced as a minimally invasive approach for the management of localized prostate cancer. ${ }^{1}$ This procedure has a steep learning curve, and one of the most difficult and critical steps to learn is the laparoscopic urethrovesical anastomosis (LUA). ${ }^{2,3}$ To reduce the learning curve and to 
improve the performance of trainees suturing a LUA, we designed a low-cost urethrovesical latex model (UVM) to teach this skill.

We hypothesized that, for complex skills such as laparoscopic urethrovesical suturing, a model incorporating task-specific surgical skills training is essential. We sought to compare the impact of taskspecific bench model training (LUA suturing on UVM) to nonspecific laparoscopic practice (basic laparoscopic suturing and knot-tying) on intracorporeal urethrovesical anastomosis performance.

\section{Methods}

The Research Ethics Boards at St. Joseph's Healthcare, and the Hamilton Health Sciences Corporation, Hamilton, Ont. approved our study. We recruited 28 senior surgical residents, fellows or staff surgeons in urology, general surgery and gynecology (Table 1 and Table 2) through surgical rounds and advertisement. We obtained informed consent from each participant and assigned them each a study identification number. We randomly assigned participants to Group 1 (task-specific) to practise on the UVM performing running LUA sutures (Fig. 1 and Fig. 2) or to Group 2 (control) to practise basic laparoscopic suturing and knot-tying on a foam pad. All participants completed a questionnaire on their laparoscopic experience (Appendix 1) and watched a 15-minute video of an actual intra- operative LUA being performed. The purpose of the video was to show how the skills chosen for this study relate to the actual procedure.

Group 1 received specific instructions on angling the needle within the needle driver, approaching and holding the urethra or bladder, setting and advancing the needle into the tissue, and when to use the opposite hand or to backhand a needle. The double-armed suture consisted of two 3-0 Prolene sutures (ETHICON, Johnson \& Johnson) $15 \mathrm{~cm}$ in length, tied tail to tail with a $\mathrm{SH}$ needle at each end. For orientation and communication purposes, while looking into the pelvis from the head in a supine position, the $12 \mathrm{o}^{\prime}$ clock position was the anterior urethra or bladder and the 6 o'clock position was the posterior urethra or bladder. We instructed participants to pass both needles out-to-in at the 6 o'clock bladder position using each arm of the suture to perform a running anastomosis up each side. They then passed 3 running anastomosis stitches connecting the bladder to the urethra from 6 to 9 o'clock on the left side and from 6 to 3 o'clock on the right side. They inserted an $18 \mathrm{Fr}$. Foley catheter from the urethral end of the model tube beyond the completed posterior half of the anastomosis. Once the catheter passed across the anastomosis, continuing the same suturing completed the anterior part of the anastomosis. When the sutures met at 12 o'clock, both were tied together with 3 knots to complete the task.

Group 2 practised suturing on foam pads

\begin{tabular}{|c|c|c|}
\hline \multirow[b]{2}{*}{ Surgical specialty; level of training } & \multicolumn{2}{|c|}{ No. of participants } \\
\hline & Group 1* & Group 2† \\
\hline Urology & 8 & 3 \\
\hline Urologists & 4 & 1 \\
\hline Fellows & 2 & 0 \\
\hline PGY-4 & 2 & 2 \\
\hline Gynecology & 2 & 5 \\
\hline Gynecologists & 1 & 2 \\
\hline PGY-5 & 1 & 2 \\
\hline PGY-4 & 0 & 1 \\
\hline General surgery & 4 & 6 \\
\hline Fellows & 2 & 2 \\
\hline PGY-5 & 2 & 2 \\
\hline PGY-4 & 0 & 2 \\
\hline All participants & 14 & 14 \\
\hline
\end{tabular}


acquired from Limbs and Things (Bristol, UK). We instructed participants to place single, simpleinterrupted sutures across the foam and tie 3 knots. Group 2 also practised running the suture across opposing straight edges of foam to practise needleand instrument-handling, but participants were not required to tie these sutures. They also received basic suture-handling and instrument-handling instructions similar to Group 1, but they did not perform any circular running sutures.

All participants received feedback from an experienced laparoscopic urologist during the practice session.
After 2 hours of training, both groups performed a post-training laparoscopic suturing test consisting of 2 tasks. The first task was to complete 5 figures of 8 and tie 3 knots on the foam pad. The second task was to perform a running LUA on the UVM (Fig. 3). For both tasks, we videotaped and timed performances. A blinded laparoscopic expert evaluated the performances using a taskspecific checklist $(\mathrm{CL})$ and global rating scale (GRS) (Appendix 2 and Appendix 3).

We performed our statistical analysis using SigmaStat Version 3.10.0 (Systat Software Inc.). From an earlier study, looking at bench model

\begin{tabular}{|c|c|c|c|}
\hline \multirow[b]{2}{*}{ Participants } & \multirow[b]{2}{*}{ Procedures } & \multicolumn{2}{|c|}{ No. of cases } \\
\hline & & Group $1^{*}$ & Group $2 \dagger$ \\
\hline $\begin{array}{l}\text { All participants } \\
\text { Urology }\end{array}$ & Laparoscopic radical prostatectomy & 0 & 0 \\
\hline \multicolumn{4}{|l|}{ All urologists } \\
\hline & Laparoscopic nephrectomy & & \\
\hline Participant \#2 & & $1-4$ & \\
\hline Participant \#3 & & 0 & \\
\hline Participant \#4 & & 0 & \\
\hline Participant \#11 & & 0 & \\
\hline Participant \#14 & & & $1-4$ \\
\hline All fellows & None performed & 0 & 0 \\
\hline All PGY-4 & None performed & 0 & 0 \\
\hline \multicolumn{4}{|l|}{ Gynecology } \\
\hline \multicolumn{4}{|l|}{ All gynecologists } \\
\hline & Diagnostic laparoscopy & $>15$ & $>15$ \\
\hline & Laparoscopic tubal ligation & $>15$ & $>15$ \\
\hline \multirow[t]{2}{*}{ All PGY- 5} & Diagnostic laparoscopy & $>15$ & $>15$ \\
\hline & Laparoscopic tubal ligation & $>15$ & $>15$ \\
\hline \multirow[t]{2}{*}{ All PGY-4 } & Diagnostic laparoscopy & & $10-15$ \\
\hline & Laparoscopic tubal ligation & & $1-4$ \\
\hline \multicolumn{4}{|l|}{ General surgery } \\
\hline \multirow[t]{3}{*}{ All fellows and PGY- 5} & Cholecystectomy & $>15$ & $>15$ \\
\hline & OGD/ERCP & $>15$ & $>15$ \\
\hline & Colonoscopy & $>15$ & $>15$ \\
\hline \multicolumn{4}{|l|}{ PGY- 4} \\
\hline \multirow[t]{3}{*}{ Participant \#8 } & Cholecystectomy & & $10-15$ \\
\hline & OGD/ERCP & & $5-10$ \\
\hline & Colonoscopy & & $5-10$ \\
\hline \multirow[t]{3}{*}{ Participant \#22 } & Cholecystectomy & & $5-10$ \\
\hline & OGD/ERCP & & $1-4$ \\
\hline & Colonoscopy & & $1-4$ \\
\hline $\begin{array}{l}\text { ERCP = endoscopic retrograde ch } \\
{ }^{*} \text { Group 1: task-specific training on } \\
\text { tGroup 2: non-task specific trainit }\end{array}$ & $\begin{array}{l}\text { oancreatography; OGD = esophagogastroduodenos } \\
\text { del. } \\
\text { e foam pad. }\end{array}$ & opy $; \mathrm{PGY}=$ pos & graduate year. \\
\hline
\end{tabular}


fidelity in ureteroscopic training, we found that the mean difference in GRS between the group that trained on the low-fidelity model and the group that underwent didactic teaching was 10.166. We calculated the pooled standard deviation as 5.0. Using $t$ test sample size calculation, to achieve a power of $80 \%$ at an $\alpha$ of 0.05 , our study required a minimum of 6 participants per group. To account for the possibility of dropouts and the differences in the complexity of the procedure and training intervention, compared with the original ureteroscopy study, we recruited an additional 8 participants per group. This allowed us to detect a difference of $15 \%$ between the 2 groups. We randomly assigned participants using sealed envelopes prepared by our statistician. We performed comparisons between Group 1 and Group 2 using a

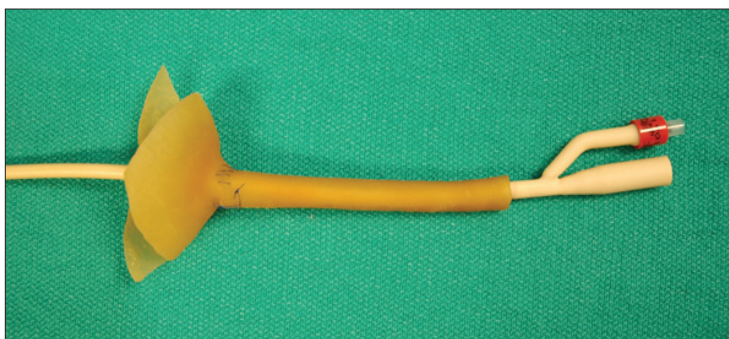

Fig. 1. The urethrovesical model sutured together with a Foley catheter passing through.
Mann-Whitney test. We considered $p<0.05$ to be statistically significant.

\section{Results}

At baseline, we detected no differences in previous laparoscopic experience, distribution of surgical specialty and level of training between groups (Table 1 and Table 2). None of the participants had performed an LRP. On the foam pad suturing task, Group 1 had significantly higher CL scores (10.9 v. 8.1, $p=0.017$ ), but we noted no significant

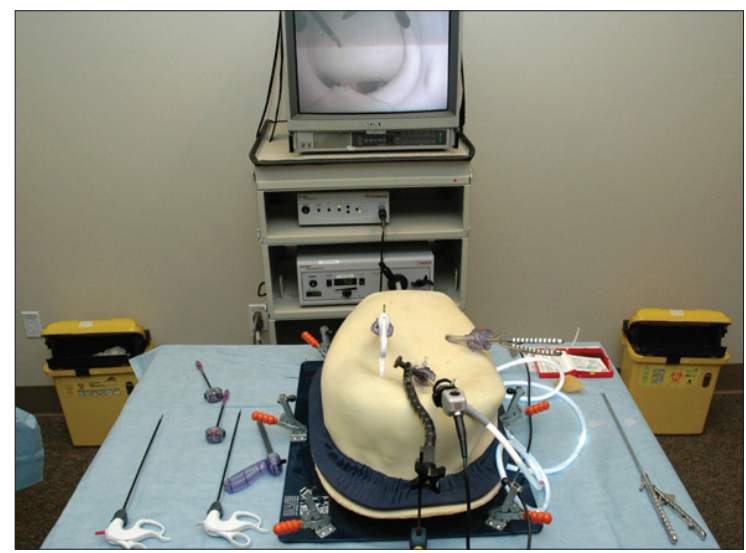

Fig. 2. Urethrovesical model positioned in the pelvic trainer simulated orientation within the male pelvis.

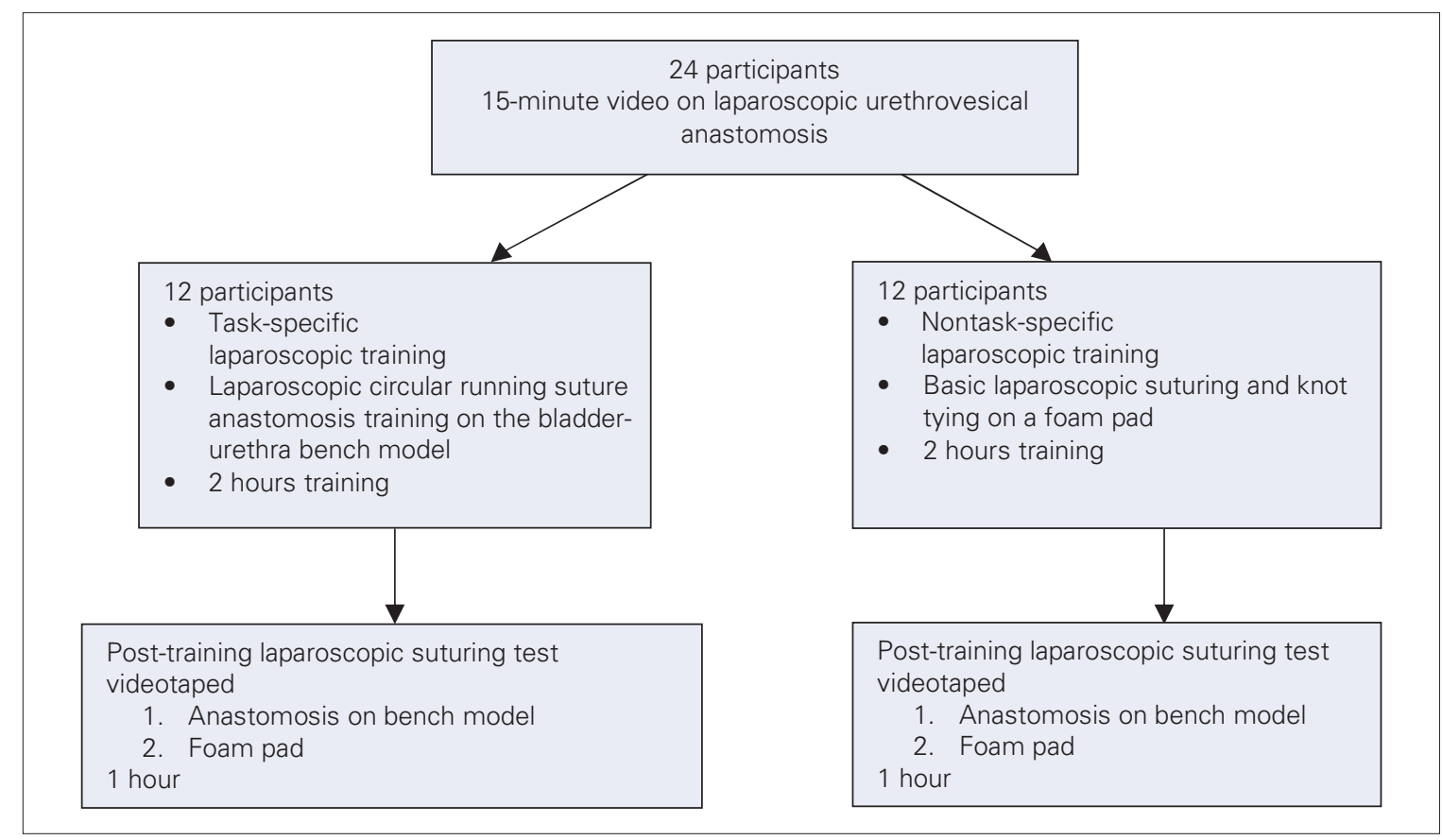

Fig. 3. Study design. 
differences in GRS or time (Table 3). On the LUA task, Group 1 had a significantly higher taskspecific CL score (10.9 v. 8.1, $p=0.017)$, GRS (29.6 v. 22.8, $p=0.005)$ and shorter times (27.6 min v. $38.3 \mathrm{~min}, p=0.004$ ) than the control group (Table 3 ).

\section{Discussion}

Reconstructive laparoscopy is technically more difficult than ablative surgery, demanding more skills and experience. With laparoscopic reconstruction, the ability to suture is a necessity. Often, suturing is performed with extreme angles and positions owing to the natural orientation of organs. In addition, suturing with standard laparoscopic needle drivers means loss of degrees of freedom. Unlike the Da Vinci robotic arm (Intuitive Surgical), which has 7 degrees of freedom because of a "wrist" within the abdominal/pelvic cavity, the pure laparoscopic surgeon has to compensate for the lack of a "wrist" by positioning and advancing a needle with a corrective angle in relation to the bladder or urethra. A urologist must learn these subtle techniques to perform a urethrovesical anastomosis successfully. Furthermore, working with instruments in the pelvis requires substantial modification of instrument-handling, suturing and tying owing to the relatively narrow confines compared with the wide-open space for transperitoneal kidney surgery.

In this study, Group 1 performed the final running urethrovesical anastomosis quicker and had

Table 3. Post-training laparoscopic suturing test results

\begin{tabular}{|c|c|c|c|}
\hline \multirow[b]{2}{*}{ Task } & \multicolumn{2}{|c|}{ Mean $\pm 95 \% \mathrm{Cl}$} & \multirow[b]{2}{*}{$p$ value } \\
\hline & Group 1* & Group $2 \dagger$ & \\
\hline \multicolumn{4}{|l|}{$\begin{array}{l}5 \text { figures of } 8 \text { and } 3 \text { knot } \\
\text { ties on the foam pad }\end{array}$} \\
\hline Time for performance, min & $22.6 \pm 3.0$ & $25.6 \pm 3.6$ & 0.15 \\
\hline Task-specific checklist/12 & $10.9 \pm 1.2$ & $8.1 \pm 1.9$ & 0.017 \\
\hline Global rating scale/35 & $29.9 \pm 3.2$ & $27.9 \pm 2.7$ & 0.17 \\
\hline \multicolumn{4}{|l|}{$\begin{array}{l}\text { Urethrovesical anastomosis } \\
\text { on the model }\end{array}$} \\
\hline Time for performance, min & $27.6 \pm 3.0$ & $38.3 \pm 6.6$ & 0.004 \\
\hline Task-specific checklist/12 & $10.9 \pm 1.2$ & $8.1 \pm 1.9$ & 0.017 \\
\hline Global rating scale/35 & $29.6 \pm 3.7$ & $22.8 \pm 3.1$ & 0.005 \\
\hline $\begin{array}{l}\mathrm{Cl}=\text { confidence interval. } \\
{ }^{*} \text { Group 1: task-specific training on } \mathrm{t} \\
\text { tGroup 2: non-task specific training }\end{array}$ & foam pad. & & \\
\hline
\end{tabular}

better CL scores and GRS compared with Group 2. This suggests that task-specific training on UVM is an effective way of learning how to perform LUA. Interestingly, Group 1 also performed the figure of 8 task better than Group 2. Training on the UVM not only led to better running urethrovesical performance, but also to better performance on simple suturing tasks.

Understanding the critical steps of a surgical procedure is important when designing bench models. The model does not have to look realistic (high fidelity) to be effective as a teaching tool. In 2 separate studies, low-cost, low-fidelity models have been shown to be effective teaching tools. ${ }^{4,5}$ However, it is important to ensure the model allows trainees to practise the essential steps required in the real procedure. In our study, the model reproduces almost all of the surgical steps of a LUA. This latex UVM has been designed to simulate anatomical and tissue characteristics (i.e., thickness) of the human bladder and urethra (Fig. 1). Operating in a man's pelvis is reproduced when the UVM is inserted into a special pelvic trainer (Limbs and Things) (Fig. 2). Not only does a trainee have the opportunity to learn proper needle position and handling, they also learn how to operate within the strict confines of the pelvic structure. Standing at the sides and working down the middle of the patient can be ergonomically taxing. With proper instructions and practice, trainees can anticipate the ergonomic challenges of laparoscopic pelvic surgery.

Several authors have proposed different models allowing trainees to acquire the skills necessary to perform an LUA. Teber and colleagues ${ }^{6}$ developed a standardized step-by-step program to improve skills and enable trainees not experienced in laparoscopy to increase reproducible performance in reconstructive laparoscopy. Katz and colleagues ${ }^{7}$ proposed a simplified 5-step model for training LUA. By using this model and dividing complicated surgical steps into simplified tasks (e.g., passage of ligature, intracorporal knotting, intracorporeal suturing, linear anastomosis, circular running suture anastomosis with chicken skin), they were able to substantially improve trainee performance. Nadu and colleagues ${ }^{8}$ developed a simple model using chicken skin in a pelvic trainer. After performing 20 anastomoses on this model, 2 urology fellows reduced the time required for performing the anastomosis from 75 to 20 minutes 
Task-specific bench model training v. basic laparoscopic skills training

and were able to create a watertight running LUA in patients in a mean time of 40 minutes (range 30-55 min). ${ }^{8}$ In our study, participants who trained on the UVM performed the urethrovesical anastomosis in a mean time of 27.6 minutes, approaching performance in the study by Nadu and colleagues. ${ }^{8}$

Other training models studied include human cadavers, live animals and virtual reality (VR) simulators to teach surgical skills. Human cadavers most closely resemble live patients but they are expensive, have limited availability, have stiffer tissues and may transmit infections. Animals remain an alternative and have the benefit of providing living simulations that are generally faithful to operative reality. However, they are expensive, necessitate specialized facilities and personnel, and are not always ethically acceptable.

Virtual reality simulators have been introduced as training tools and could improve the performance in the operating room for laparoscopic surgery. ${ }^{9-12}$ For example, a VR simulator named URO Mentor (Simbionix) is commercially available for training in endourology. Several studies have shown that training on the simulator improves performance. ${ }^{13-15}$ However, studies validating VR simulators in the operating room are limited. Simulators also lack haptics (tactile feedback), which is essential in procedures such as laparoscopy.

There were limitations with our study. The urethrovesical anastomosis is an essential step in performing an LRP, yet there are preceding steps that have to be learned and consolidated before finishing with the anastomosis. This study focused only on a single step, and it is important to keep in mind that a successful procedure requires multiple steps to be completed successfully. From an educational perspective, the ability to deconstruct a procedure into steps and create an inventory is attractive, as this facilitates teaching and evaluation of complex surgeries. The challenge would be to find a teaching model that incorporates all of the critical steps to teach a new procedure from beginning to end. With advances in graphics and virtual haptics, VR may provide the solution for the acquisition of complex skills.

Other limitations include the lack of intraoperative factors such as blood and urine, which can hamper surgical performance. We included only participants at an advanced level in a specialty where laparoscopy is currently used; however, our population is homogeneous in the sense that none of the participants had ever performed an LRP. Owing to the limited number of urologists and urology residents in our area and program, we could not rely on them exclusively to reach our sample size. Another limitation of this study is model validation. The ideal validation method would have been to perform the post-test on a patient, but for ethical reasons such as the participants' lack of experience, the transfer to this "highfidelity model" would be unacceptable. A more suitable high-fidelity model would be a live anesthetized pig, as the pig urethrovesical junction and the pelvic dimensions have anatomical and tissue characteristics similar to humans. The second phase of our study will research whether skills learned on the UVM transfer to a high-fidelity live pig model.

\section{Conclusion}

Laparoscopic urethrovesical anastomosis is one of the most challenging steps during an LRP. We have developed a task-specific bench model that allows a trainee to practise LUA. Training on this model is superior to basic laparoscopic suturing practice. The second phase of our study will assess whether skills learned on the UVM leads to a better urethrovesical anastomosis on a live anesthetized pig.

From * Sherbrooke University, Department of Surgery, Division of Urology, Sherbrooke, Que., and †McMaster University, Department of Surgery, Division of Urology, Hamilton, Ont.

This article has been peer reviewed.

Competing interests: None declared.

\section{References}

1. Zorn KC, Lee, BR. Laparoscopic radical prostatectomy: an established minimally invasive procedure with proven oncologic track record. J Endourol 2008;22:2053-5.

2. Stolzenburg JU, Katsakiori PF, Liatsikos EN. Role of laparoscopy for reconstructive urology. Curr Opin Urol 2006;16:413-8.

3. Poulakis V, Witzsch U, De Vries R, et al. Intensive laparoscopic training: the impact of a simplified pelvic-trainer model for the urethrovesical anastomosis on the learning curve. World I Urol 2006;24:331-7.

4. Anastakis D., Regehr G, Reznick R, et al. Assessment of technical skills transfer from the bench training model to the human model. Am J Surg 1999;177:167-70.

5. Matsumoto ED, Hamstra SJ, Radomski SB, et al. The effect of bench model fidelity on endourological skills: a randomized controlled study. J Urol 2002;167:1243-7.

6. Teber D, Dekel Y, Frede T, et al. The Heilbronn laparoscopic training program for laparoscopic suturing: concept and validation. J Endourol 2005;19:230-8.

7. Katz R, Nadu A, Olsson LE, et al. A simplified 5-step model for training LUA. J Urol 2003;169:2041-4 
Sabbagh et al.

8. Nadu A, Olsson L., Abbou CC. Simple model for training in the laparoscopic vesicourethral running anastomosis. J Endourol 2003;17:481-4.

9. Korndorffer JR Jr, Dunne JB, Sierra R, et al. Simulator training for laparoscopic suturing using performance goals translates to the operating room. J Am Coll Surg 2005; 201:23-9.

10. Seymour NE, Gallagher AG, Roman $\mathrm{SA}$, et al. Virtual reality training improves operating room performance: results of a randomized, double-blinded study. Ann Surg 2002; 236:458-63.

11. Shah J, Darzi A. Virtual reality flexible cystoscopy: a validation study. BJU Int 2002; 90:828-32.

12. Ogan K, Jacomides L, Shulman MJ, et al. Virtual ureteroscopy predicts ureteroscopic proficiency of medical students on a cadaver. J Urol 2004;172:667-71.

13. Watterson JD, Beiko DT, Kuan JK, et al. Randomized prospective blinded study vali- dating acquistion of ureteroscopy skills using computer based virtual reality endourological simulator. J Urol 2002;168:1928-32.

14. Jacomides L, Ogan K, Cadeddu JA, et al. Use of a virtual reality simulator for ureteroscopy training. J Urol 2004;171:320-3.

15. Wilhelm DM, Ogan K, Roehrborn CG, et al. Assessment of basic endoscopic performance using a virtual reality simulator. J Am Coll Surg 2002:195:675-81.

Correspondence: Dr. Edward D. Matsumoto, McMaster University, Department of Surgery, Division of Urology, McMaster Institute of Urology at St. Joseph's Hospital, 50 Charlton Ave. E., Hamilton ON L8N 4A6; fax 905 308-7205; matsumo@mcmaster.ca

\section{Appendix 1. Participant questionnaire}

Candidate no.

How many of the following procedures have you performed by yourself? (i.e. $>80 \%$ of the procedure)

$\begin{array}{llllll}\text { 1. laparoscopic prostatectomy } & 0 & 1 \text { to } 4 & 5 \text { to } 10 & 10 \text { to } 15 & >15 \\ \text { 2. laparoscopic nephrectomy } & 0 & 1 \text { to } 4 & 5 \text { to } 10 & 10 \text { to } 15 & >15 \\ \text { 3. laparoscopic cholecystectomy } & 0 & 1 \text { to } 4 & 5 \text { to } 10 & 10 \text { to } 15 & >15 \\ \text { 4. OGD/ERCP } & 0 & 1 \text { to } 4 & 5 \text { to } 10 & 10 \text { to } 15 & >15 \\ \text { 5. colonoscopy } & 0 & 1 \text { to } 4 & 5 \text { to } 10 & 10 \text { to } 15 & >15 \\ \text { 6. Other laparoscopic } & 0 & 1 \text { to } 4 & 5 \text { to } 10 & 10 \text { to } 15 & >15\end{array}$

procedure many of the following procedures have you assisted at? (i.e. $<80 \%$ of the procedure)

$\begin{array}{llllll}\text { 1. laparoscopic prostatectomy } & 0 & 1 \text { to } 4 & 5 \text { to } 10 & 10 \text { to } 15 & >15 \\ \text { 2. laparoscopic nephrectomy } & 0 & 1 \text { to } 4 & 5 \text { to } 10 & 10 \text { to } 15 & >15 \\ \text { 3. laparoscopic cholecystectomy } & 0 & 1 \text { to } 4 & 5 \text { to } 10 & 10 \text { to } 15 & >15 \\ \text { 4. OGD/ERCP } & 0 & 1 \text { to } 4 & 5 \text { to } 10 & 10 \text { to } 15 & >15 \\ \text { 5. colonoscopy } & 0 & 1 \text { to } 4 & 5 \text { to } 10 & 10 \text { to } 15 & >15 \\ \text { 6. other laparoscopic } & 0 & 1 \text { to } 4 & 5 \text { to } 10 & 10 \text { to } 15 & >15\end{array}$
procedure

How many of the following procedures have you seen?

$\begin{array}{llllll}\text { 1. laparoscopic prostatectomy } & 0 & 1 \text { to } 4 & 5 \text { to } 10 & 10 \text { to } 15 & >15 \\ \text { 2. laparoscopic nephrectomy } & 0 & 1 \text { to } 4 & 5 \text { to } 10 & 10 \text { to } 15 & >15 \\ \text { 3. laparoscopic cholecystectomy } & 0 & 1 \text { to } 4 & 5 \text { to } 10 & 10 \text { to } 15 & >15 \\ \text { 4. OGD/ERCP } & 0 & 1 \text { to } 4 & 5 \text { to } 10 & 10 \text { to } 15 & >15 \\ \text { 5. colonoscopy } & 0 & 1 \text { to } 4 & 5 \text { to } 10 & 10 \text { to } 15 & >15 \\ \text { 6. } \text { other laparoscopic } & 0 & 1 \text { to } 4 & 5 \text { to } 10 & 10 \text { to } 15 & >15\end{array}$
procedure

$E R C P=$ endoscopic retrograde cholangiopancreatography; $O G D=$ esophagogastroduodenoscopy. 


\section{Appendix 2. Participant questionnaire*}

Task-specific checklist

Item

$1 \quad$ Needle loaded one-half to two-thirds from tip

2 Uses laparoscopic needle holder and graspers to handle needle

Needle enters tissues at right angles (80\% of bites)

Single attempt at needle passage through tissues ( $90 \%$ of bites)

$\begin{array}{cc}\text { Not done or incorrect } & \text { Done correctly } \\ 0 & 1 \\ 0 & 1 \\ 0 & 1 \\ 0 & 1 \\ 0 & 1 \\ 0 & 1 \\ 0 & 1 \\ 0 & 1 \\ 0 & 1 \\ 0 & 1 \\ 0 & 1 \\ 0 & 1\end{array}$

Follow through on curve of needle on entrance ( $80 \%$ of bites)

Follow through on curve of needle on exit ( $80 \%$ of bites)

Minimal damage with graspers

Equal spacing

Equal bites on each side ( $80 \%$ of bites)

Square knots

Apposition of tissues without excessive tension on suture

12 Appropriate alignment of tissues (no torsion)

Maximum total score

Total score

*Adapted from task-specific checklist used in the Objective Structured Assessment of Technical Skills (OSATS). (Reznick R, Regehr G, MacRae H, et al. Testing technical skill via an Innovative "Bench Station" Examination. Am J Surg 1997:173:226-30. 


\section{Appendix 3. Global rating scale}

Candidate identification no.

Please rate the candidate's performance on the following scale:

Respect for tissue

1

2

3

4

5

Frequently used unnecessary force on tissue or cased damage by inappropriate use of instruments

Careful handling of tissue but occasionally Consistently caused inadvertent damage

handled tissues appropriately with minimal damage

Time and motion

2

Many unnecessary moves

$$
1
$$

\section{2}

handling

Knowledge of instruments

Repeatedly makes tentative or awkward moves with instruments by inappropriate use of instruments

$$
1
$$

Frequently asked for wrong instrument or used inappropriate instrument

\section{2}

Flow of operation

$$
1
$$

Frequently stopped operating and seemed unsure of the next move

\section{2}

Consistently placed assistants poorly or failed to use assistants

\section{2}

Knowledge of specific procedure

Deficient knowledge. Needed specific instruction at most steps
3

Efficient time/motion but some unnecessary moves

$$
3
$$

Competent use of instruments but occasionally appeared stiff or awkward$$
3
$$$$
4
$$

Clear economy of movement and maximum efficiency

\section{5}

Fluid moves with instruments and no awkwardness

Knew names of most instruments and used Obviously familiar appropriate instruments

with the

instruments and their names

$$
3
$$

4

5

Demonstrated some forward planning with reasonable progression of procedure

$$
3
$$

4

Appropriate use of assistants most of the time

\section{3}

4

\section{Knew all important steps of operation}

Obviously planned course of operation with effortless flow from one move to the next

\section{5}

Strategically used assistants to the best advantage at all times

\section{5}

Demonstrated familiarity with all aspects of operation

Would you feel confident in allowing this trainee to perform this procedure in the operating room?

Yes

No 